\title{
Real Fire Test on Concrete Columns and Post-tensioned Slabs
}

\author{
IAN BENNETTS and WARREN SOUTH* \\ Centre for Sustainable Infrastructure \\ Swinburne University of Technology \\ Hawthorn, Victoria, Australia \\ ${ }^{*}$ Cement Concrete and Aggregates Australia \\ Sydney, Australia
}

\begin{abstract}
An enclosure fire test was conducted incorporating high strength reinforced concrete columns and normal strength post-tensioned floor slabs. The slabs formed part of the roof whilst the columns within the enclosure were unloaded except for compressive stresses induced by the prestressing bar located at the centre of each of the columns. The columns and slabs were made from commonly available but markedly different Australian aggregates. Some of the columns incorporated $6 \mathrm{~mm}$ monofilament polypropylene (pp) fibres introduced into the concrete mix at a concentration of $1 \mathrm{~kg} \mathrm{per} \mathrm{m}^{3}$ of concrete. With the exception of columns with pp fibres, spalling commenced within 10 minutes of the start of the test with all columns experiencing extreme spalling. The test was terminated at 68 minutes due to failure of one of the posttensioned slabs. Minimal spalling was obtained for slabs constructed from basaltic aggregate. The implications of the findings are considered with respect to the design of reinforced concrete structures.
\end{abstract}

KEYWORDS: High-strength concrete, spalling, post-tensioned slabs, fire test.

\section{INTRODUCTION}

The purpose of the testing described in the paper was aimed at providing an improved understanding into the behaviour of high strength concrete columns and post-tensioned concrete slabs made from concretes incorporating common Australian aggregates when subject to a natural enclosure fire. Due to their common commercial use, Nepean River gravel (NSW) and basaltic (Vic) aggregates were chosen for the test described in this paper.

The issue of spalling in fire has long been considered for both normal and high strength concretes. Much of the early fire testing on normal strength concretes undertaken prior to 1980 was for columns with characteristic compressive strengths of up to $45 \mathrm{MPa}$. An early assessment of this data [1] (172 standard fire tests) found that spalling occurred in almost 30\% of cases with the level of spalling varying from minor to very severe (although this was only observed in very few instances). Early CEB/FIP recommendations [2] for minimum member size and cover when compared with this available test data gave an adequate and slightly conservative prediction of fire resistance in most situations. Early versions of the Australian concrete structures code AS 3600 were based on Ref [2] whilst the latest version of AS 3600 [3] is based on values given by EC2 [4].

Early work on the spalling of normal weight concretes in fire concluded that spalling is influenced by moisture content, aggregate type and aspects of member geometry (thin versus thick). The use of higher strength concretes, particularly for columns and tunnel linings, is now commonplace with concretes having a characteristic strength of $80 \mathrm{Mpa}$ or greater being commonly used in the construction industry in Australia. The behaviour of high strength concrete in fire has been the subject of many investigations $[5,6]$ with the beneficial effect of various lengths of polypropylene fibres in reducing spalling being noted. The use of such fibres is seen as enabling the relief of high internal pressures due to the melting of the fibre at relatively low temperatures and consequently the creation of pathways to enable the relief of internal vapour pressure.

Kodur [7-9] reported the results of standard fire tests conducted on normal and high strength concretes. The normal strength concrete had a compressive strength of around 35MPa whilst the high strength concrete had a compressive strength of around 95MPa. Limestone aggregates were used for some of the normal and high strength columns and a lesser amount of spalling was detected for concretes made from these aggregates. For the high strength concrete columns it was found that there was no significant spalling in the first 30 minutes but as the tests proceeded, spalling progressed and was reported as being significant just before the end of the tests - which ranged in duration from 108 to 343 minutes. Comparing the behaviour 
of high strength columns with and without polypropylene fibres, it was found that the fire resistance was greatly improved with the addition of such fibres. It appeared that the use of ties at a closer spacing or better restrained ties had some beneficial effect, presumably because as the columns began to deform laterally, the addition ties were more effective in keeping the concrete in place.

Bostrom et al [10] present the results of an evaluation of spalling behaviour for concretes using different mixes and specimens. The work was undertaken to consider the use of concrete in buildings and for tunnel linings. For concretes considered for tunnel linings, specimens were subject to a severe fire test considered to represent a tunnel fire. Other specimens were subject to the standard time temperature curve identical to that given in ISO 834 and considered to be relevant for fires in buildings. In this case, the heating period applied to the specimens was 60 minutes and the specimens were a mixture of larger slabs and beams and smaller specimens. The cube strengths of the concretes tested varied from $73 \mathrm{MPa}$ to $107 \mathrm{MPa}$. For specimens tested under standard fire test conditions spalling was common except where polypropylene fibres were incorporated. In this case, the test specimens were small slabs and long cylinders. However, even with the addition of polypropylene fibres, spalling occurred with specimens subjected to the more severe heating curve, however the amount of spalling was much less than that associated with specimens without fibres. It was found that the likelihood of spalling is increased if the specimen is subjected to compression and it was postulated that this limits the formation of cracks on the exposed face that would enable the relief of pressure. This was found to be the case even at low levels of compression such as $2.5 \mathrm{Mpa}$.

Bailey and Lennon [11] describe two real fire tests on prestressed hollow core planks. The tests incorporated the planks as the roof of the test enclosure which was $17.76 \mathrm{~m}$ wide and $7.02 \mathrm{~m}$ deep. Ventilation openings to provide air for combustion were provided in one of the long sides. The intent of this test was to demonstrate that a floor system (as opposed to isolated elements) could readily resist a serious fire. Superimposed loads were applied to the floor slabs which were constructed from concrete having a 28 day cube strength of $85.7 \mathrm{MPa}$. Previous testing of isolated members under standard fire test conditions suggested that such floor members could undergo premature shear failure. The "natural" fires associated with these tests had fire severities equivalent to $60-80$ minutes of standard fire test exposure. Only slight and localised spalling was noted during the fires and the floor system resisted the imposed load despite a significant vertical displacement (close to $400 \mathrm{~mm}$ ) at midspan.

Kelly and Purkiss [12] consider that flat slabs and columns are particularly prone to spalling. They reviewed the results of a fire test on a post-tensioned slab constructed from Thames River gravel observing that this member experienced significant spalling after 11 minutes of exposure to heating associated with the standard time-temperature curve given in ISO 834. The floor slab failed prematurely with exposure of one of the prestressed ducts due to loss of concrete below the duct.

It is clear that spalling of concrete in fire can significantly reduce the fire resistance of concrete members with the most vulnerable members being columns and slabs. Spalling appears to be more likely with high strength concrete than normal strength concrete with the use of various quantities of polypropylene fibres within high strength concrete mixes apparently improving the spalling resistance. The properties of the coarse aggregates used within the concrete mix may also contribute to spalling. Post-tensioned slabs are considered to be vulnerable to spalling. It is for these reasons that the test described in this paper was undertaken on high-strength columns and normal strength post-tensioned slabs made from concretes incorporating common Australian aggregates.
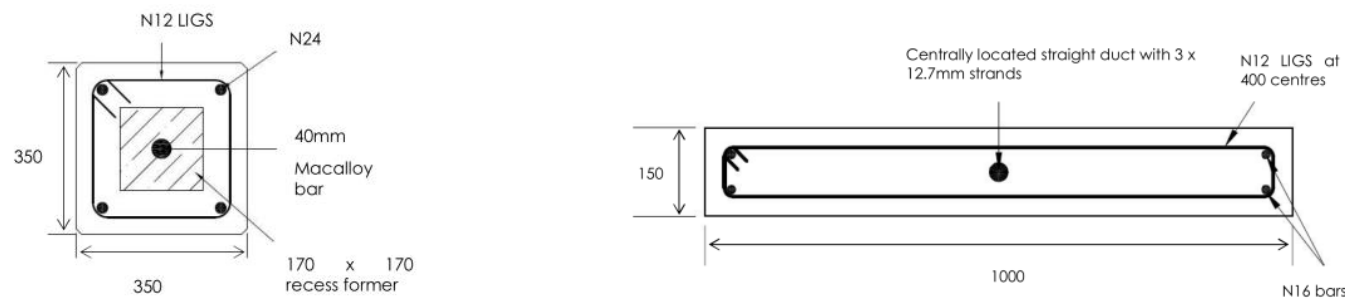

Figure 1 Cross-section of Typical Column and Slab 


\section{TEST SPECIMENS}

The post-tensioned slabs were constructed from normal strength concrete whilst all columns were constructed from high strength concrete. The concrete strengths are summarised in Table 1. Details of the members tested are given in Table 2 with the cross-sectional reinforcing details and dimensions shown in Figure 1. All of the 12 columns had the same cross-sectional dimensions and longitudinal reinforcement and all were $3 \mathrm{~m}$ in length. Each column incorporated a high strength Macalloy bar which was stressed to induce a minimum level of compression into the column. This was done since it was not possible to otherwise load the columns and the presence of a level of compression was considered likely to enhance the likelihood of spalling.

It will be noted that 6 columns were constructed from high strength concrete made from Nepean River gravel and 6 from concrete made from local basalt. For each set of 6 columns made from each type of aggregate, 2 incorporated $8 \mathrm{~mm}$ monofilament fibres and had standard tie spacing $(200 \mathrm{~mm})$, two has closer tie spacing $(120 \mathrm{~mm})$ and no fibres and 2 had no fibres and standard tie spacing. Petrographical details for the basalt and Nepean River gravel have been detailed in a separate reference [13].

Three post-tensioned slabs were constructed - two from normal strength concrete containing basalt and one with concrete incorporating Nepean River gravel. All slabs were $6 \mathrm{~m}$ long and incorporated some nominal reinforcement to enable handling after casting and a centrally placed flat duct containing $3 \times 12.7 \mathrm{~mm}$ strands. As with the Macalloy bars for the columns, the strands were also tensioned approximately one month after casting.

Table 1 Concrete strengths at Maximum Age of Testing

\begin{tabular}{|l|c|c|}
\hline \multicolumn{1}{|c|}{ Concrete Mix } & Age (days) & Strength (Mpa) \\
\hline Basalt High Strength & $(28) 56$ & $(88) 96$ \\
\hline Basalt Normal Strength & 28 & 34 \\
\hline Nepean High Strength & $(28) 56$ & $(74.5) 89$ \\
\hline Nepean Normal Strength & 28 & 43.5 \\
\hline
\end{tabular}

Table 2 Detail of Test Specimens

\begin{tabular}{|l|l|l|l|l|l|l|l|}
\hline $\begin{array}{l}\text { Ref } \\
\text { No. }\end{array}$ & $\begin{array}{l}\text { Aggregate } \\
\text { Type }\end{array}$ & PP Fibres? & $\begin{array}{l}\text { Tie } \\
\text { Spacing } \\
(\mathrm{mm})\end{array}$ & $\begin{array}{l}\text { Ref } \\
\text { No. }\end{array}$ & $\begin{array}{l}\text { Aggregate } \\
\text { Type }\end{array}$ & $\begin{array}{l}\text { PP } \\
\text { Fibres? }\end{array}$ & $\begin{array}{l}\text { Tie } \\
\text { Spacing } \\
(\mathrm{mm})\end{array}$ \\
\hline C1 & basalt & No & 200 & $\mathbf{C 7}$ & Nepean & No & 200 \\
\hline C2 & basalt & No & 200 & C8 & Nepean & No & 200 \\
\hline C3 & basalt & No & 120 & C9 & Nepean & No & 120 \\
\hline C4 & basalt & No & 120 & C10 & Nepean & No & 120 \\
\hline C5 & basalt & Yes & 200 & C11 & Nepean & Yes & 200 \\
\hline C6 & basalt & Yes & 200 & $\mathbf{C 1 2}$ & Nepean & Yes & 200 \\
\hline S1 & basalt & No & 400 & S3 & Nepean & No & 400 \\
\hline S2 & basalt & No & 400 & & & & \\
\hline
\end{tabular}

On the day of casting, the columns without polypropylene fibres were cast first (i.e. 4 columns). Polypropylene fibres were then added to the mixing truck at a dosage rate of $1 \mathrm{~kg}$ per $\mathrm{m}^{3}$ of concrete and then the concrete was mixed for 10 minutes prior to casting the last two columns. The fibres added to the mix were $6 \mathrm{~mm}$ monofilament polypropylene fibres. No fibres were added to the normal strength concrete mixes for the slabs. Compression cylinders were taken from each mix during concrete casting. No cylinders 
were taken from the mix with fibres since it is known that the presence of fibres will have little effect on compressive strength.

Tensioning of the steel was undertaken at the casting yard before all specimens were transported to the Large Fire Test Facility at the CFA training centre at Fiskville, Victoria, where they were stored under cover. The Large Fire Test Facility is operated by the Centre for Environmental Safety and Risk Engineering (CESARE) at Victoria University.

Allowing for the hole through the centre of each column specimen for the prestressing bar and for the presence of the four reinforcing bars, the prestressing result in an axial stress some distance away from the ends of almost 7MPa. Similarly, away from the ends of the slabs, the compressive stress induced by the prestressing was about $3 \mathrm{MPa}$.

\section{TEST SET-UP}

\section{Test Enclosure}

The fire test enclosure was constructed within the CESARE Large Fire Test Facility operated by Victoria University in Victoria, Australia. This building contains roof and wall vents and has been designed to allow the conduct of significant fire tests in a controlled environment.

The key performance requirements for the test enclosure were to contain a fire of sufficient severity and to provide support for the prestressed concrete slabs spanning across the top of the enclosure. It was considered that the enclosure must contain the fire and continue to support the slabs for at least one hour since a fire that lasts for this length of time would adequately test the ability of the concrete elements to resist the effects of spalling.

The heat transferred to a concrete element is a complex function of the air and wall temperatures and the temperature of the outer surfaces of the concrete element. Initially, because the concrete is cool, heat transfer to the concrete elements will be at a maximum since it depends on the difference in these temperatures. Temperatures measured by thermocouples within an enclosure are taken as being representative of the fire temperatures at the thermocouple locations.

It was decided to use timber cribs as the heating source since timber provides a ready means of fuel and more than $90 \%$ of the combustibles within real enclosures are made from cellulosic materials. In any case, the temperatures achieved in an enclosure are more dependent on the quantity of fuel and ventilation than the type of fuel. It is noted that the burning rate and therefore the rate of heat release (RHR) within enclosures is generally taken as being proportional to $\sum A \sqrt{h}$ where $A$ is the area of a wall opening to outside and $h$ is the height of that particular opening. However, not all combustible gases generated within the enclosure will burn within the enclosure.

The fire temperatures experienced within an enclosure (as measured by thermocouples) are a function of the RHR but also the thermal mass of the enclosure and its contents. At the early stages of a fire, the energy released is absorbed by the boundaries, specimen surfaces and the air within the enclosure. If there are significant cold boundaries, then the fire temperatures will be lower. As the boundaries and surfaces get hotter, less energy is absorbed by the boundaries and surfaces and the temperatures measured within the enclosure become higher.

Prior to designing the test rig, an analysis of the proposed enclosure incorporating the concrete members was undertaken using FDS to determine the RHR required to achieve fire temperatures of between 900 and $1000^{\circ} \mathrm{C}$ - which are considered to be representative temperatures for significant real fires. It was found that a RHR of around 10MW would achieve such temperatures assuming that non-concrete surfaces were insulated to prevent further heat losses. Accordingly, these surfaces were lined with a mineral fibre blanket to reduce the heat losses early in the fire.

Due to the uncertainties associated with the above calculations, additional openings were added as was a mechanism to reduce the level of ventilation throughout the test.

The enclosure utilised a steel supporting frame that was clad on the inside with fire-resistant plasterboard and a layer of ceramic fibre insulation blanket. The end walls containing the openings were clad on the outside by further layers of fire-resistant plasterboard.

Due to the weight and difficulty of handling the columns, the construction sequence was to erect three of the walls and then move the columns into position before attaching the final wall. The slabs were lifted on 
to the supporting frame after all of the walls had been erected. In addition to the slabs (each $1 \mathrm{~m}$ wide), ceiling sections consisting of $25 \mathrm{~mm}$ of ceramic fibre (on innermost face) and two layers of $16 \mathrm{~mm}$ fire resistant plasterboard were designed to span between the side walls of the test enclosure and placed at each end of the test enclosure so as to complete the roof. The inside dimensions of the enclosure measured $4250 \mathrm{~mm} \times 5400 \mathrm{~mm}$ when measured between the insulated walls. The height to the soffit of the slabs from the floor was $3300 \mathrm{~mm}$.

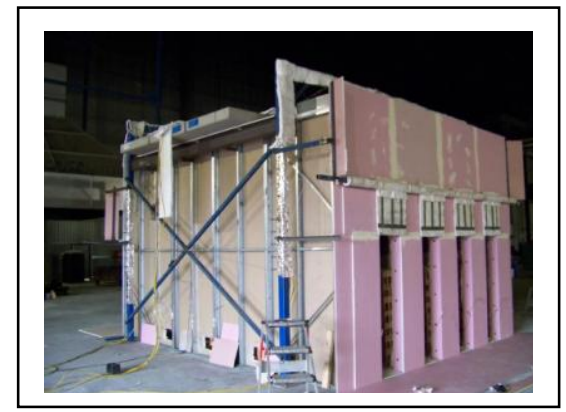

Figure 2 View of Test Enclosure with Slabs supported over Top

The ventilation openings into the enclosure consisted of four $1800 \mathrm{~mm} \times 465 \mathrm{~mm}$ openings at each end and three low level openings on the other sides to allow more air into the enclosure should it be considered that the fire did not have sufficient severity. An adjusting facility was also provided to limit the height of the openings at each end so as to reduce the fire severity should this be considered necessary. The adjuster can be seen in Figure 2.

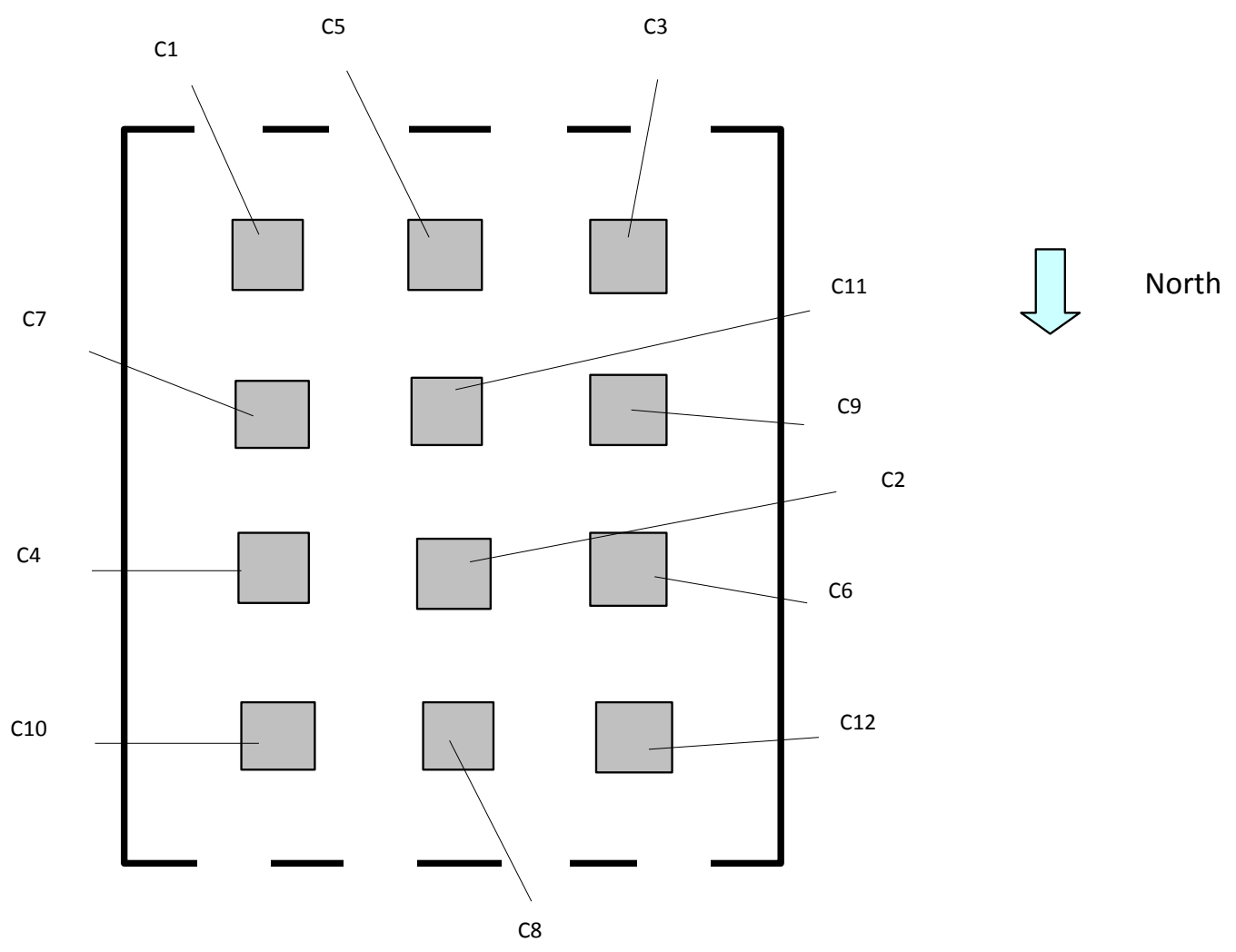

Figure 3 Plan view showing position and orientation of columns within enclosure

The top of each of the columns was insulated with two layers of $16 \mathrm{~mm}$ fire-resistant plasterboard to ensure that the end anchorages would not be exposed to excessive heat through the ends of the columns. This was 
an extra precaution since the anchorages at the ends of the columns are already protected by about 50mm of concrete.

The faces of the columns were $800 \mathrm{~mm}$ apart. Similarly, the distance between the outer face of a column and the inside face of the enclosure wall was $800 \mathrm{~mm}$ and were positioned within the enclosure as shown in Figure 3 whilst the position of the slabs placed over the top of the enclosure and forming part of its ceiling is shown in Figure 4. The end ceiling panels that completed the roof of the enclosure are also shown. The clear span between the supports for the slabs was $5100 \mathrm{~mm}$.

\section{Test Fire Load}

The fire load within the enclosure consisted of 20 timber cribs. Before finalising the choice of crib the burning behaviour of the preferred crib was determined by conducting a test below the CESARE furniture calorimeter. A sustained maximum RHR of about 1.2MW was obtained for the crib when burnt in the open. The cribs were made by cutting 45 x 90 pine timber sections into $630 \mathrm{~mm}$ lengths and forming cribs with successive layers each having 7 pieces of timber. Adjacent sticks of timber were $60 \mathrm{~mm}$ apart.

The 20 cribs were places equidistant between columns (innermost cribs) and equidistant between the columns and the internal walls of the enclosure in the case of the cribs adjacent to the enclosure walls. The eight cribs closest to the main ventilation openings had 14 such layers whilst the rest had 17 layers. The total mass of fuel within the enclosure was $2850 \mathrm{~kg}$ giving an average fire load per unit area of $(2850 /(4.25$ $x$ 5.4)) or $124 \mathrm{~kg} / \mathrm{m}^{2}$. In addition to the timber fuel, one litre of methylated spirits was placed below each crib in an aluminium tray. This liquid was place into the trays just prior to the commencement of the test by pouring via plastic tubing from outside of the test enclosure.

\section{Instrumentation}

Two layers of thermocouples were provided within the test enclosure. The uppermost layer, numbered $1-$ 20 were located $400 \mathrm{~mm}$ down from the soffit. The second layer, numbered $21-40$ was positioned approximately $1500 \mathrm{~mm}$ below the soffit but in the same locations when viewed from above. The positions for the uppermost layer are shown in Figure 5.

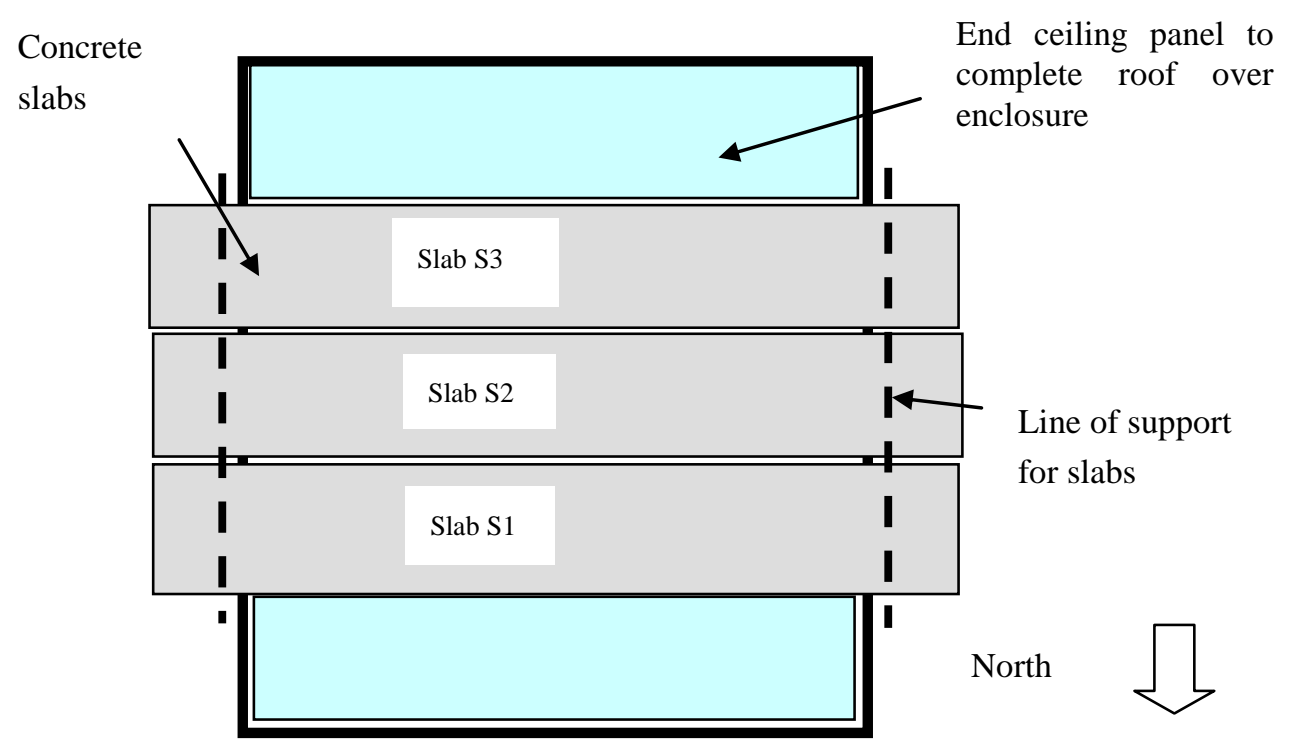

Figure 4 Positioning of Slabs over the top of Enclosure

When viewed in plan, the thermocouples were located in the east-west direction midway between the faces of the columns or midway between faces of the columns and the internal walls of the enclosure in the case of the columns closest to the walls. The thermocouples were mineral insulated $3 \mathrm{~mm}$ diameter Type K. They were located down from the top of the enclosure by placing them between and through the mineral fibres insulation located between the slabs or between the slabs and the end roof panels. Eight thermocouples were located through the end roof panels via holes through the plasterboard linings. 


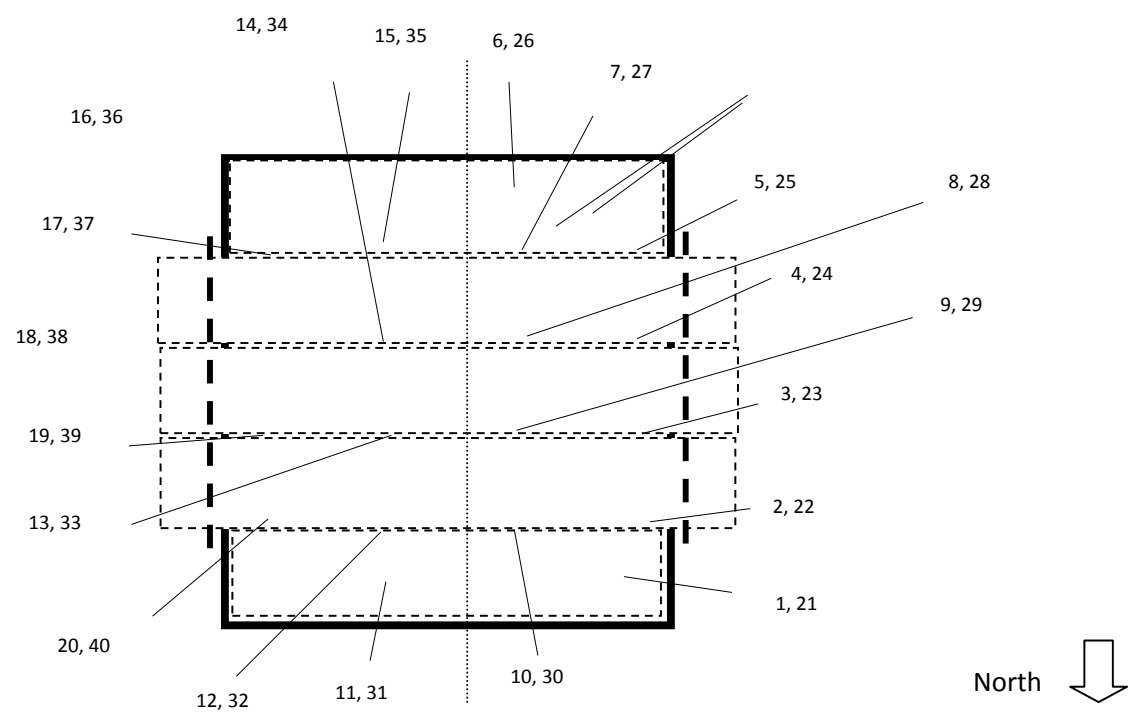

Figure 5 Locations of Thermocouples in Plan

The associated PVC cabling was run across the top of the roof, down the sides and finally to the temperature measurement instrumentation. The PVC cabling was protected as much as possible from heat. This was a necessary precaution due to the possibility of significant deformation of one of the slabs that could result in flames being emitted from between the slabs - or from flames coming from the openings at each end.

\section{TEST AND FINDINGS}

\section{Introduction}

The fire was initiated by igniting the methylated spirits in each of the aluminium trays at the bottom of the cribs. This was achieved by remote electrical ignition. A view of the burning cribs shortly after ignition is shown in Figure 6.

After ignition of the cribs, significant external burning and flaming was noted at both ends of the enclosure - but particularly at the south end (Figure 7). The temperatures within the enclosure were being constantly monitored and it was considered necessary to reduce the south end ventilation so as to increase the quantity of heat energy being released within the enclosure. This was done using the ventilation closing mechanism. The openings at the south end were maintained at the original height. The low level openings were blocked and subsequently opened depending on the temperatures achieved in the enclosure. During the test, spalling occurred and generated various types of sound which were recorded by the external video recorders.

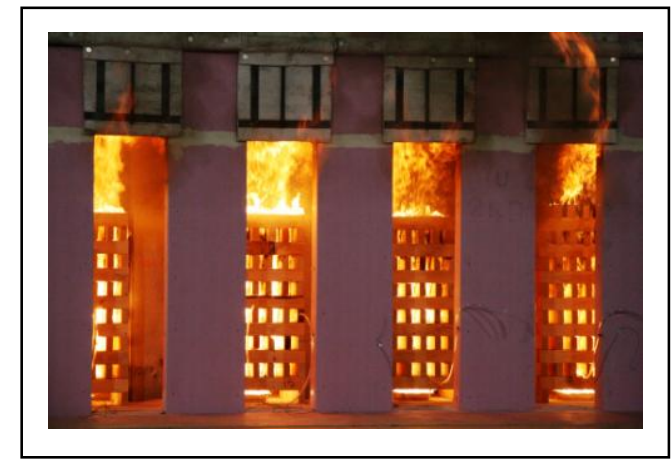

Figure 6 Burning Cribs

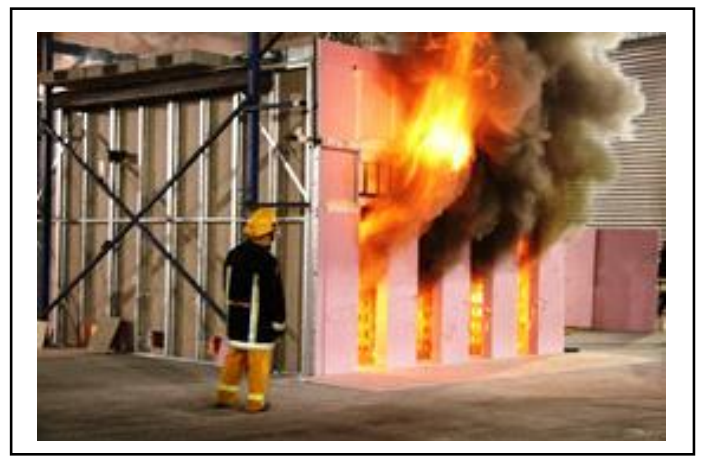

Figure 7 Flames emitted from openings 
Spalling of the columns commenced at 10 minutes after the start of the test and was accompanied by mainly "explosive" sounds. This was also noted at 12,13,16, 20, 24 minutes and then more or less continuously up to about 50 minutes, after which the frequency reduced and such sounds were replaced by a rapid and loud high frequency continuous cracking sound (staccato) that has previously been observed in other tests to be associated with the loss of smaller pieces of concrete including the fracturing of aggregate. Such staccato sounds also commenced about 10 minutes after the start of the test, but occurred on a more intermittent basis but with much less intensity than that which occurred at around the 50 minutes mark. This intense staccato sound occurred up to the end of the test and appeared to be associated with Slab S3.
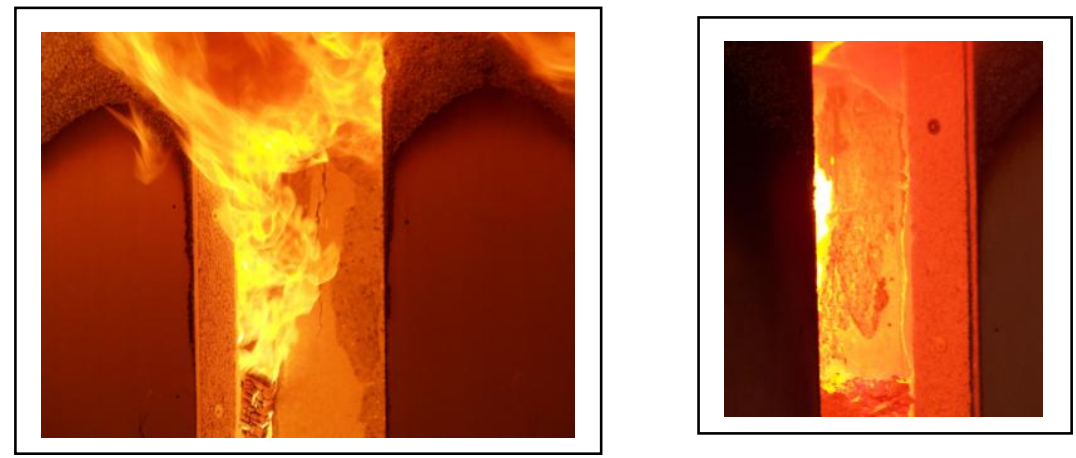

Figure 8 Photos showing spalled columns through flames

Views of the spalled concrete columns at the 30 minute mark are given in Figure 8 . In some cases, the "explosive" spalling resulted in pieces of concrete being ejected through the openings of the enclosure on to the floor of the test building.

At 61 minutes, a major crack developed in slab S3 causing the slab to move upwards at the crack and allow flames to pass out of the gap formed at the edge of the slab. This is shown in Figure 9. The test was stopped at 68 minutes due to concern about the broken slab. This was done by reducing the north ventilation and then carefully placing water on the burning fuel so as not to wet the columns. Once the fuel bed had been sufficiently cooled, the north wall of the enclosure was removed and photographs were taken. These are shown in Figure 10.

\section{Temperatures}

The gas temperatures within the enclosure for the uppermost layer of thermocouples (i.e. the layer located $400 \mathrm{~mm}$ below the soffit) are plotted in Figure 11. Also shown in this figure is the standard time temperature curve (STTC) used for heating of elements of construction during standard fire tests according to ISO 834.
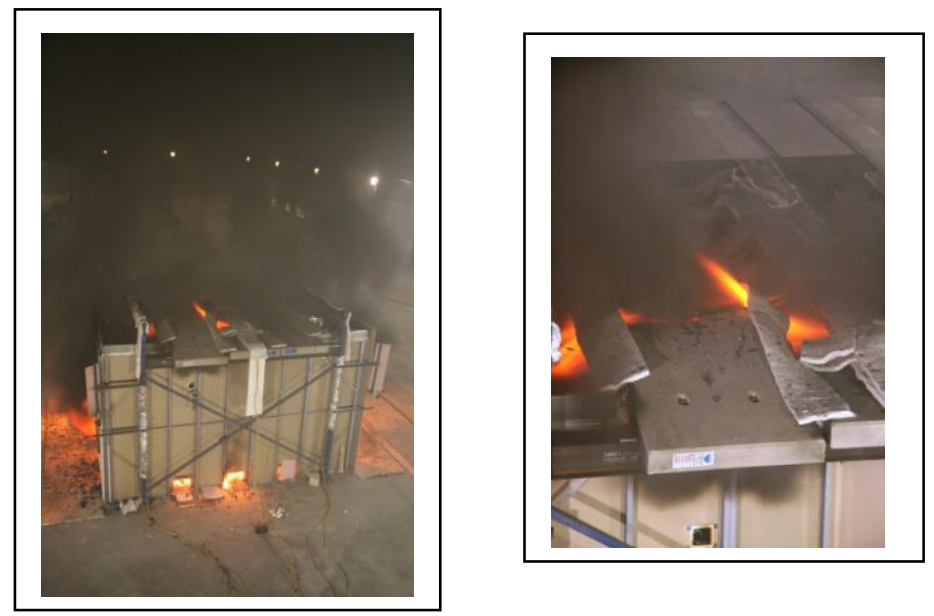

Figure 9 Fracture and failure of Slab S3 at 61 minutes

It was noted that the bottom layer of temperatures were marginally higher than the toper at various locations but for both sets of thermocouples, the localised maximum temperatures exceeded the STTC by 
up to $200^{\circ} \mathrm{C}$ at the early stages and $100^{\circ} \mathrm{C}$ at later stages. However, the average enclosure temperatures at any time were lower than the STTC. At around 60 minutes, the temperatures become more uniform and began to increase significantly. This is thought to be due to the fact that the fuel had essentially turned into a charcoal fuel bed with heat being released more efficiently and with the enclosure surfaces radiating more effectively back into the enclosure.

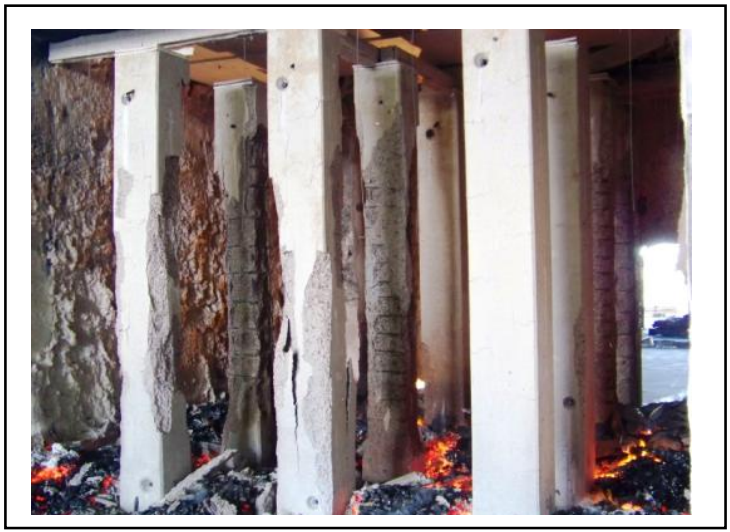

Figure 10 View of columns just after fire with north wall removed

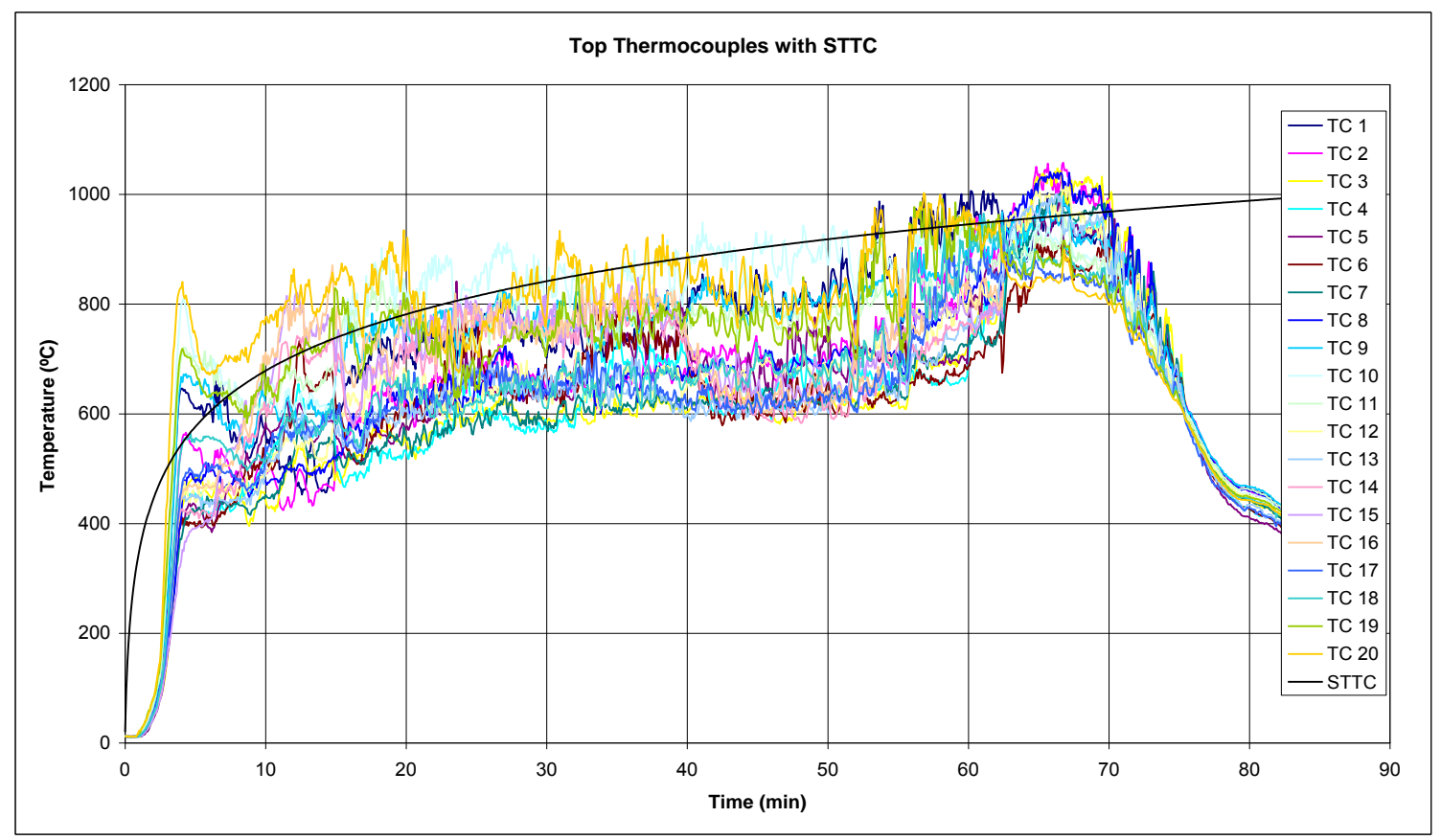

Figure 11 Temperatures as recorded by top level

\section{Spalling}

All of the columns except for those with polypropylene fibres suffered significant spalling. The comparison in behaviour is illustrated in Figure 12 which shows column C10 (no fibre) and column C12 (fibre). Extensive photographs of the columns were taken and diagrammatic records made of the depth of spalling at the most severely affected cross-section. Generally the maximum depth of spalling at locations was to the rear of the ties but in the case of columns $\mathrm{C} 1, \mathrm{C} 2, \mathrm{C} 3$ and $\mathrm{C} 4$ (all basalt aggregates) the depth of spalling extended past the inside of the ties (Figure 13).

In the case of the columns made from concrete with fibre, the column that behaved best was $\mathrm{C} 12$ with no loss of concrete whilst the other columns $(\mathrm{C} 5, \mathrm{C} 6, \mathrm{C} 11)$ lost concrete at particular locations from one corner (C5, C11) or two corners (C6) (Figure 14). 

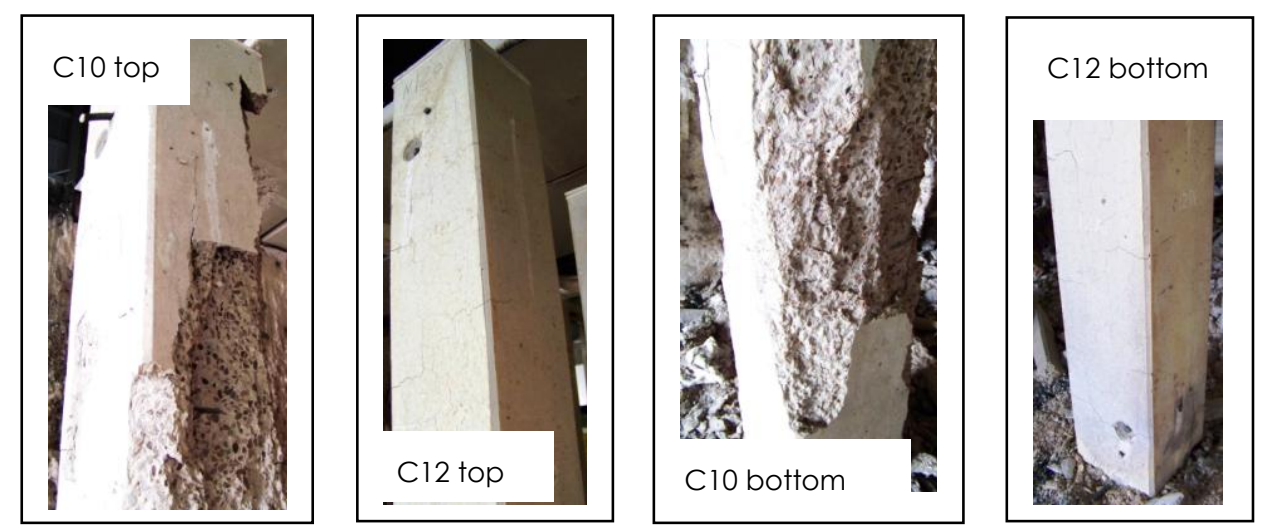

Figure 12 Comparisons of Columns C10 and C12
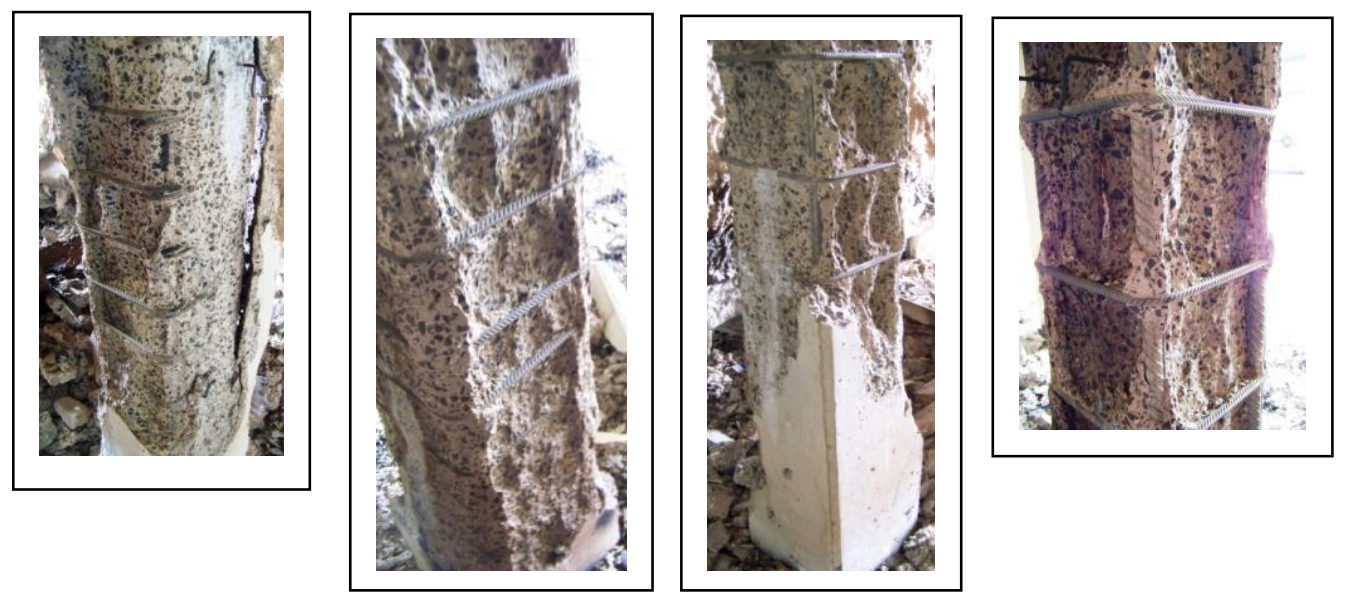

Figure 13 Spalling associated with Columns C1 -C4
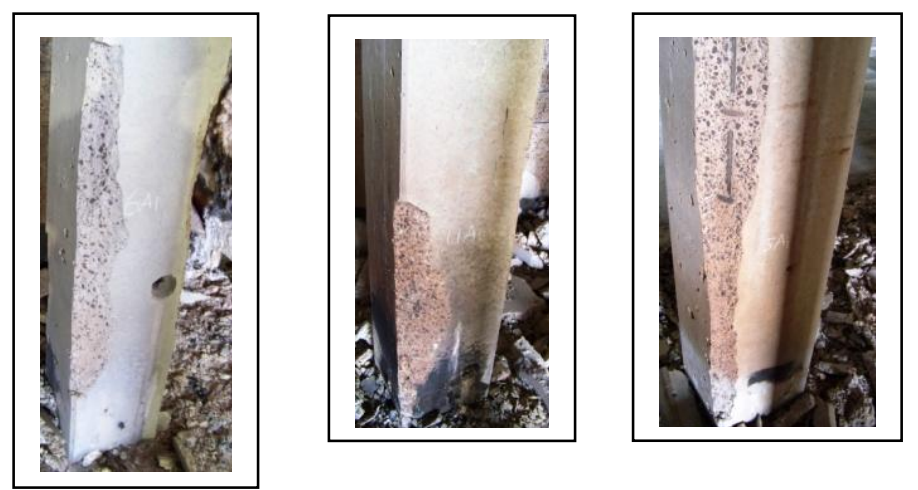

Figure 14 Corner spalling of columns with fibre

As far as the slabs were concerned, Slab S2 exhibited no spalling at all whereas Slab S1 exhibited spalling at the ends of the slab below the anchorages (Figure 15) but not elsewhere. The spalling at the east end of the slab measured approximately $750 \mathrm{~mm} \times 600 \mathrm{~mm}$ in area and was $30 \mathrm{~mm}$ deep whilst that at the other end was slightly less in area but 40mm deep.

Figure 16 shows Slab S3 after the test and the associated extensive spalling. In this case the reinforcement and prestressing duct were completely exposed with the depth of spalling exceeding one half the depth of 
the slab. It will be noted from Figure 16 that the slab appears to have displaced upwards. This, at first sight, is a surprising outcome. However, as spalling progressed the self-weight of the slab would have been significantly reduced and this would have resulted in the overhang with greater mass tending to displace
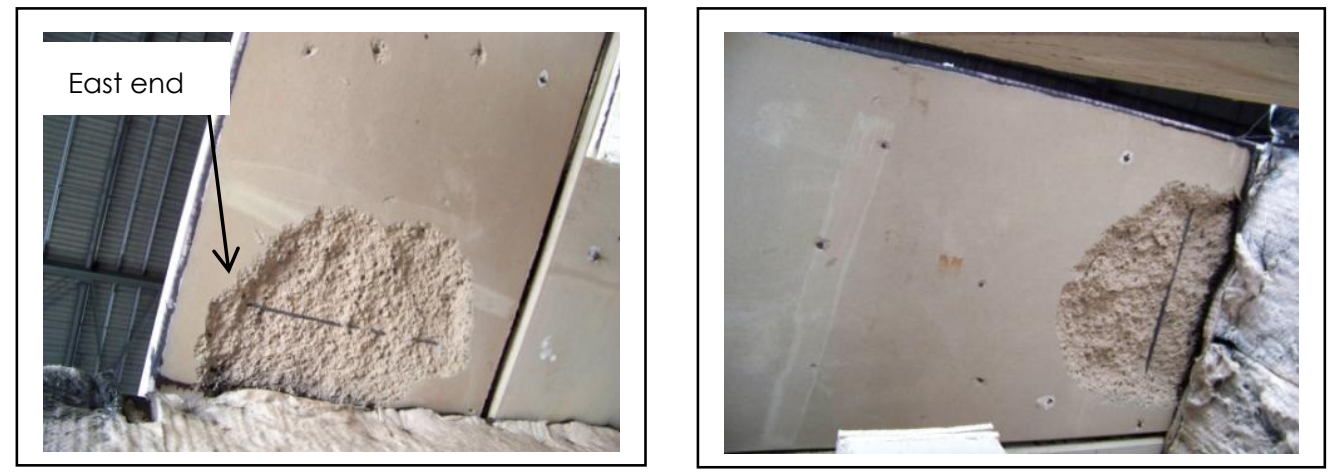

Figure 15 Localised Spalling at the ends of Slab S1

downwards especially with loss of flexural strength at the crack due to progressive spalling. The sudden upwards movement of the slab is probably explained by reduction of compressive resistance at one location due to spalling such that the residual force in the prestressing tendons caused the slab to move upwards resulting in failure of the concrete at this location resulting in formation of the observed crack across the width of the slab. The slab was able to remain in this position due to the tendon acting as a tie and the slab and associated top reinforcement forming an arch. The resultant self-weight was therefore supported by tied arch action and the mass associated with the overhangs. Subsequent examination of the tendon indicated that this was substantially intact and therefore had not failed during the test.

The exposed surface of the slab suggested that most of the exposed surface appeared to have experienced a "pitting" type of spalling and this would well have corresponded to the staccato spalling noise mentioned previously. This appears to have been associated with fracture of the aggregate.

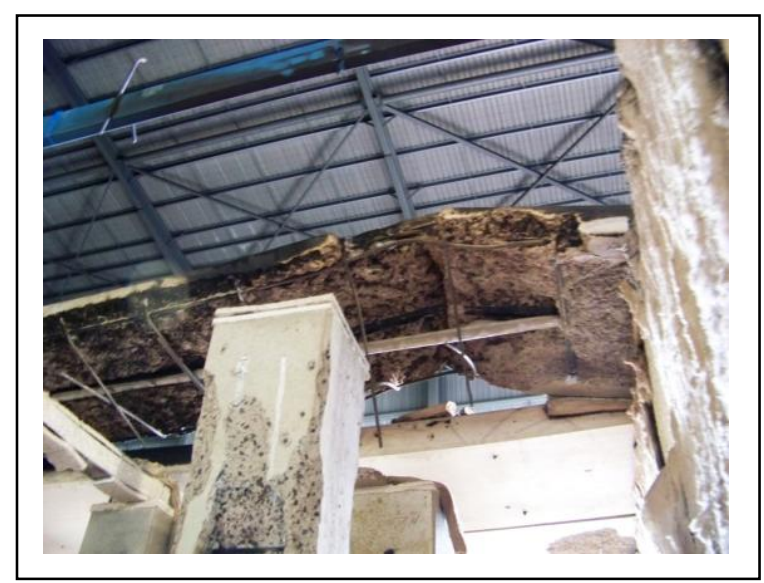

Figure 16 View of Slab S3 showing spalling

\section{DISCUSSION OF FINDINGS}

The heat energy transferred to a concrete member is a function of the fire temperature and the heat transfer relationships between the fire and the concrete surfaces. The hotter the fire, as measured by the air temperature measuring thermocouples, the more heat will be transferred to the concrete elements. It can be seen from Figure 11 that the air temperatures are similar to those associated with the standard time temperature curve which is used as the basis for the grading periods specified in the Building Regulations. Thus, the severity of the test fire was similar to that which would be experienced with standard fire test exposure of around 60 minutes of exposure. This outcome was not by design but was the result of the thermal mass within the enclosure and the ventilation conditions. 
The difference in behaviour of Slabs S1 and S2 is difficult to explain except to note that the result is an indication of the normal variability associated with fire testing. A comparison of the air temperatures just below the slabs suggest that the temperatures were similar and therefore the difference in behaviour cannot be attributed to significant differences in temperature throughout the test. It is noted that the compressive stresses associated with the soffit of the slab are highest near the ends of the slab. This is due to the fact that the force from the end anchorage must be distributed into the slab over a finite distance and that there is an absence of significant bending stresses at this location. It has been previously noted that the presence of compressive strains appears to increase the likelihood of spalling.

Slabs 1 and 2 were constructed from concrete utilising basalt aggregate, whereas Slab S3 incorporates Nepean River gravel. If the test results are to be taken at face value, the behaviour of Slab S3 would suggest that normal strength concrete utilising the latter aggregate is prone to significant spalling when used in a prestressed slab. However, this is a single test.This apparent behaviour contrasts with that observed for the high-strength columns where those constructed using concrete incorporating Nepean River Gravel appeared to behave marginally better than those with concrete incorporating basalt aggregates. The difference in behaviour may be related to the ability of the higher strength matrix to limit the spalling mechanism noted for slab S3 which appeared to be related to aggregate behaviour. More research is required to better understand the apparent difference in behaviour and to better assess the spalling behaviour of normal strength concrete made from Nepean River gravel.

The behaviour of columns without polypropylene fibres is now considered. All of these columns suffered serious spalling. The spalling experienced ranged from large pieces (1-2kg) being blown off to smaller pieces being removed on a more or less continuous (staccato) basis. It is noted that the depth of spalling appears to be greater for the columns with basalt aggregate concrete where spalling went well within the column ties at various locations (see Figure 13). The temperatures adjacent to the columns have been considered and it is found that these temperatures were slightly higher for the columns containing Nepean River Gravel. Thus the difference in fire temperature cannot be used to explain the apparent difference in spalling depth.

The addition of polypropylene fibres to the concrete makes a very great difference as far as spalling resistance is concerned. This is true for columns made from both types of aggregate. As noted previously, only one column (C12) exhibited an absence of spalling whilst the others (C5, C6 and C11) exhibiting relatively minor spalling. The spalling associated with these columns appeared to involve pieces being lost from the corners. It is not understood why this occurred but it is thought to have been due to inadequate fibres in this location.

It is noted that the locations of corner spalling for columns containing fibres were all associated with the column face containing the lifting lugs - i.e. the uppermost face during casting. Following casting of the columns without fibre, the fibre was added to the mix but by this time the workability of the mix had reduced and placement of concrete within the formwork required considerable compaction. The significance of this requires further consideration and it would be helpful to undertake research to study the effect of compaction of $\mathrm{pp}$ fibre distribution in a concrete member given that the addition of such fibres appears to limit the workability of the concrete mix.

The placement of ties at closer spacing than normal was found to have no influence on the level of spalling but this is probably due to the fact that such a measure will only be effective in situations where the column is subject to significant curvature as might be experienced near the end of a test of a fully loaded member.

As noted in the introduction to this paper, Kelly and Purkiss [12] reported the advent of severe spalling with a post-tensioned slab constructed from Thames River Gravel - a common aggregate in the UK. Similar behaviour was demonstrated by Slab S3.

It is interesting to note that in the large-scale natural test described by Bailey [14] the supporting columns which were constructed from limestone aggregates (known to perform better in fire) and with pp fibres added at a rate of $2.7 \mathrm{~kg} / \mathrm{m}^{3}$ showed little but not a complete absence of spalling showing similar behaviour to that shown in Figure 14. 


\section{CONCLUSIONS}

High strength concrete columns and post-tensioned normal strength concrete slabs were subjected to real fire exposure within a purpose-built enclosure. The severity of fire exposure was similar to that which would have been experienced if the members had been tested under standard fire test conditions. The concretes used in the testing incorporated aggregates that are commonly used in Australia.

Unless polypropylene fibres are added to the mix for high strength concrete columns, severe spalling is likely to occur. This appears to be true irrespective of the type of aggregate - i.e. basalt or Nepean River gravel. The addition of $6 \mathrm{~mm}$ monofilament polypropylene fibres at a dosage rate of $1 \mathrm{~kg} / \mathrm{m}^{3}$ to the concrete mix had a dramatic effect in reducing the level of spalling. This is consistent with overseas test data and findings although higher concentrations are often added and the length of the fibres is sometimes longer. Consideration needs to be given adequate mixing and compaction on site. It is strongly recommended that structural designers contemplating the use of high strength concrete columns for major buildings insist on the addition of polypropylene fibres to the concrete mix at a dosage rate of at least $1 \mathrm{~kg} / \mathrm{m}^{3}$.

The post-tensioned slab constructed from Nepean River gravel spalled badly and further research is required to better understand this behaviour which appeared to involve fracture of the aggregate. Research could also be undertaken to determine whether the spalling mechanism can be altered by the concrete strength. This may explain the differences in spalling behaviour of the high-strength concrete columns and the prestressed slab S3 since both types of member were constructed with concrete incorporating Nepean River gravel..

One of the slabs constructed from basalt aggregate exhibited no spalling whereas the other slab, of nominally identical construction, spalled at each end of the slab. No reason is offered for the difference in behaviour except that it could be due to normal fire test variability. Further testing is recommended. It is likely that the addition of polypropylene fibres to the concrete mix would have minimised the spalling at the ends of Slab S1.

\section{ACKNOWLEDGEMENT}

The authors would like to acknowledge the financial support of Cement Concrete and Aggregates Australia (CCAA) and the significant technical contribution and support of the late Dr Samia Guirguis (formerly CCAA Technical Director).

\section{REFERENCES}

1. Bennetts, I.D., "Behaviour of Concrete Elements in Fire", Part 2, Research Report No. MRL/PS23/82/005, BHP Melbourne Research Laboratories, Nov 1982

2. Guide to Good Practice (1975), FIP/CEB Recommendations for the Design of Reinforced and Prestressed Concrete Structural Members for Fire Resistance.

3. Standards Australia, AS3600 - 2009, "Concrete Structures"

4. Bennetts, I.D., "Behaviour of Concrete Elements in Fire”, Part 2, BHP Melbourne Research Laboratories Report No. MRL/PS23/82/005, Nov 1982

5. Mendis, P., "Design of high-strength concrete members: state-of-the-art", Progress in Structural Engineering and Materials, 2004, 5, pp1-15

6. Aldea, C-M., Franssen, J.M. and Dotreppe, J-C., Paper B7 "Fire Test on Normal and High-Strength Reinforced Concrete Columns" in NIST Special Publication 919 "International Workshop in Fire Performance of High-Strength Concrete, NIST, Gaithersburg, MD, Feb 13-14, 1997

7. Kodur, V. and Phan, L., "Critical factors governing the fire performance of high strength concrete systems”, Fire Safety Journal, 42 (2007), pp482 - 488

8. Kodur, V.K.R., "Guidelines for Fire Resistance Design of High-strength Concrete Columns”, Journal of Fire Protection Engineering, 2005, 15, pp 93 - 106

9. Kodur, V.K.R. and McGrath, R., "Effect of silica fume and lateral confinement on fire endurance of high strength concrete columns", Canadian Journal of Civil Engineering, 33, pp 93 - 102, 2006 
10. Bostrom, L., Wickstrom, U and Bijan, A-Z., "Effect of specimen size and loading conditions on spalling of concrete", Fire and Materials, 2007, 31: 173-186

11. Bailey, C.G. and Lennon, T., "Full-scale fire tests on hollowcore floors", The Structural Engineer, March, 2008

12. Kelly, F. and Purkiss, J., "Reinforced concrete structures in fire: a review of current rules", The Structural Engineer, October, 2008

13. Bennetts, I.D., "Real Fire Test on Concrete Elements", Noel Arnold and Associates Report, Aug 2009, Australia

14. Bailey, C., "Holistic behaviour of concrete buildings in fire", proc of Institution of Civil Engineers, Structures and Buildings, 52, Aug 2002, Issue 3, pp 199-212 